\title{
Parameterizing sub-surface drainage with geology to improve modeling streamflow responses to climate in data limited environments
}

\author{
C. L. Tague ${ }^{1}$, J. S. Choate ${ }^{1}$, and G. Grant ${ }^{2}$ \\ ${ }^{1}$ University of California, Santa Barbara, USA \\ ${ }^{2}$ USDA Forest Service, Pacific Northwest Research Station, Corvallis, Oregon, USA \\ Correspondence to: C. L. Tague (cltague@ bren.ucsb.edu) \\ Received: 7 June 2012 - Published in Hydrol. Earth Syst. Sci. Discuss.: 18 July 2012 \\ Revised: 30 November 2012 - Accepted: 12 December 2012 - Published: 29 January 2013
}

\begin{abstract}
Hydrologic models are one of the core tools used to project how water resources may change under a warming climate. These models are typically applied over a range of scales, from headwater streams to higher order rivers, and for a variety of purposes, such as evaluating changes to aquatic habitat or reservoir operation. Most hydrologic models require streamflow data to calibrate subsurface drainage parameters. In many cases, long-term gage records may not be available for calibration, particularly when assessments are focused on low-order stream reaches. Consequently, hydrologic modeling of climate change impacts is often performed in the absence of sufficient data to fully parameterize these hydrologic models. In this paper, we assess a geologic-based strategy for assigning drainage parameters. We examine the performance of this modeling strategy for the McKenzie River watershed in the US Oregon Cascades, a region where previous work has demonstrated sharp contrasts in hydrology based primarily on geological differences between the High and Western Cascades. Based on calibration and verification using existing streamflow data, we demonstrate that: (1) a set of streams ranging from 1st to 3rd order within the Western Cascade geologic region can share the same drainage parameter set, while (2) streams from the High Cascade geologic region require a different parameter set. Further, we show that a watershed comprised of a mixture of High and Western Cascade geologies can be modeled without additional calibration by transferring parameters from these distinctive High and Western Cascade end-member parameter sets. More generally, we show that by defining a set of endmember parameters that reflect different geologic classes, we
\end{abstract}

can more efficiently apply a hydrologic model over a geologically complex landscape and resolve geo-climatic differences in how different watersheds are likely to respond to simple warming scenarios.

\section{Introduction}

One of the key challenges in providing spatially distributed streamflow information is the limitation of data that is available for hydrologic model calibration and parameterization (Beven, 2001; Singh and Woolhiser, 2002; Wagener and Wheater, 2006). Implementing hydrologic models typically requires calibration of a number of drainage-related parameters that cannot be directly measured (Beven, 2001). Most recent model-based studies of climate-warming impacts on hydrology within the Western US have used historic streamflow records for model calibration (Knowles and Cayan, 2002; Christensen et al., 2004; Hidalgo et al., 2009; Jung and Change, 2010; Null et al., 2010). Climate change impact assessments in the Western US address streamflow changes across multiple scales and for multiple basins, ranging from impacts on larger-order streams that provide water supply to impacts on smaller headwater streams that support aquatic habitat (Farley et al., 2011). Particularly when assessments are focused on multiple streams and lower order stream reaches, long-term gage records may not be available for calibration. The limited availability of hydrologic data is further exacerbated by the steady decline in the USGS streamflow gauging network (USGS, 1999). Hydrologic modeling 
studies often assume that parameters used for a larger gaged watershed can be consistently applied to smaller subwatersheds, or that parameters from neighboring watersheds can be used. Calibration based on gauges from a larger order watershed however, does not necessarily apply to the diversity of lower order streams within that watershed. Similarly, parameter transfer from neighboring watersheds may not be appropriate. In this paper we present a relatively simple strategy for parameter transfer based on geologic similarity. We hypothesize that for regions with sharp geologic contrasts, we can develop end-members parameter sets based on geologic classification that can be used to parameterize hydrologic models across a range of scales without additional calibration.

Parameter transfer schemes, where parameters are assigned based on some readily measured watershed characteristics, offer one approach for assigning drainage parameters when estimates of streamflow across a range of watersheds are needed. In fact, when drainage parameters are assigned based on calibration of a larger watershed, streamflow estimates for nested subcatchments implicitly transfer parameters and assume similarity of those parameters across the larger watershed. Studies on parameter transfer have used watershed size, elevation, and vegetation as a basis for transferring parameters between watersheds with varying degrees of success (e.g., van der Linden and Woo, 2003; Wagener and Wheater, 2006). These studies focus on overall model performance using different parameter schemes, but do not explicitly address implications for estimating climate change impacts. Evaluation of parameter transfer schemes, calibration approaches, and model performance in general should ultimately reflect the context in which the model is being used. How good is good enough depends on the modeling goal.

Drawing on an example from the snow-dominated mountains of the Cascades in Western Oregon, here we evaluate parameter transfer approaches in the context of assessing climate change impacts on streamflow. Our broader focus is on the analysis of drainage parameter transfer within the framework of snowmelt-dominated watersheds in the mountainous Western US, and the use of hydrologic models to estimate how streamflow seasonality in these watersheds will respond to a warming climate. The hydrology of mountain regions throughout the globe is expected to be highly vulnerable to a warming climate (Barnett et al., 2005). In snow-dominated regions, warmer temperatures can reduce the amount of precipitation falling as snow and lead to earlier snowmelt, particularly at elevations where the majority of precipitation falls near $0^{\circ} \mathrm{C}$ (Nolin and Daly, 2006). These changes in snow dynamics shift the timing of seasonal hydrographs, resulting in increased flow in winter and reductions during spring and summer (Knowles and Cyan, 2002; Barnett et al., 2005; Stewart et al., 2005). Process-based hydrologic models are one of the core tools used to project how water resources in these systems are likely to respond to climate variability and change.

In this study, we investigate drainage parameter variation and its implication for hydrologic model-based estimates of seasonal streamflow responses to climate warming within the McKenzie River watershed in Western Oregon. Our approach applies a process-based hydro-ecological model, the Regional Hydro-Ecologic Simulation System (RHESSys), and focuses on the estimation of seasonal streamflow response to climate change at multiple spatial scales. We propose an end-member mixing approach to parameter transfer, where end-member sub-watersheds are defined based on geologic classification and used to estimate spatial patterns of drainage parameters. We then examine the utility of this parameter transfer strategy within the context of predicting inter-annual variation in seasonal streamflow patterns and streamflow response to climate warming in the snowdominated watersheds of the Oregon Cascades.

\section{Background}

Ensemble climate model predictions for the mountain regions of the US Pacific Northwest (PNW) predict temperature increases of between 1 and $4^{\circ} \mathrm{C}$ (Payne et al., 2004). Both empirical and model-based analyses in the PNW also link recent and projected future increases in air temperatures with reduced summer water availability (Tague et al., 2008; Hayhoe et al., 2004). This study focuses on tributaries of the McKenzie River, which is itself a tributary of the Willamette River in Oregon. The Willamette River watershed is one of the largest river systems in Oregon, and drains $28672 \mathrm{~km}^{2}$ to its mouth at the Columbia River. The McKenzie River watershed is one of several large tributaries of the Willamette that drains from the Cascade crest westward before joining the Willamette in its northward flow. The McKenzie River watershed, at $3463 \mathrm{~km}^{2}$, accounts for approximately $12 \%$ of the Willamette's total drainage. Streamflow within the McKenzie supports agriculture, aquatic biota, recreation, power generation, and municipal water supplies. Climate change impacts on the seasonality of flow, particularly reductions in summer flows when discharges are already low, will affect these water uses. Climate impact assessments for these multiple water uses will require estimates of the impact of climate variability and change in streamflow at multiple scales (Farley et al., 2011). For example, headwater reaches in the McKenzie support threatened fish species, such as Oregon Bull Trout and Chinook salmon (US EPA, 2003). At larger scales, flows are regulated by several large reservoirs primarily operated by the US Army Corps of Engineers within the McKenzie to provide power generation and flood protection.

For the McKenzie and other similar snow-dominated watersheds, a key hydrologic issue is how changing snow accumulation and snowmelt translate into changes in streamflow. There are two primary controls on this response: (1) how 
spatial patterns of snow accumulation and melt change, and (2) how those changes in input translate into changes in streamflow behavior (Fig. 1). The latter is primarily controlled by subsurface drainage characteristics. Changes in evapotranspiration fluxes are a 3rd factor and can become increasingly important when climate change substantially alters vegetation structure through disturbances. A significant research focus in the Western US has been on improving models of snow accumulation and melt, as well as spatially explicit estimates of climate forcing functions (Daly et al., 1994). Translating these effects into streamflow change however, also requires adequate estimates of subsurface drainage characteristics. Our previous work has demonstrated that within the McKenzie, geologically mediated spatial differences in subsurface drainage characteristics can be a 1st order control on spatial patterns of streamflow response to warming (Tague and Grant, 2009). Subsurface drainage characteristics reflect both topography, which is relatively easy to parameterize given the widespread availability of DEMs, and effective subsurface conductivity of watersheds, where conductivity is a complex product of matric- and macropore flow rates and their distribution (Troch et al., 2009). In most hydrologic modeling studies, parameters associated with effective conductivity, such as hydraulic conductivity and macropore distributions, are calibrated or assumed to be spatially uniform. Given that subsurface drainage properties evolve through landscape evolutionary processes, one might expect that these parameters would vary across geological classification (Jefferson et al., 2006, 2010). Empirical studies and models based on streamflow patterns in the Oregon Cascades support this assertion (Tague and Grant, 2004, 2009).

Within the McKenzie River watershed, sharp geologic contrasts exist between two largely contiguous geologic provinces: (1) the Plio-Pleistocene High Cascades (HC) to the east, and (2) the primarily Miocene Western Cascades (WC) to the west (Sherrod and Smith, 2000). Elevations range from 400 to $1800 \mathrm{~m}$ in the WC and from $1500 \mathrm{~m}$ to over $3400 \mathrm{~m}$ at the summits of the large stratovolcanoes in the HC. Although the $\mathrm{HC}$ region has the highest elevations, much of the landscape is a broad constructional platform with relatively low relief; the WC is much steeper and more dissected. Young basaltic lava flows dominate the $\mathrm{HC}$ province while older lava flows and volcaniclastic rocks dominate the WC province. These distinctions drive hydrologic flowpath differences and residence times (Jefferson et al., 2006). The young lava flows in the HC have exceptionally high permeability with high vertical hydraulic conductivity, resulting in a greater portion of deep groundwater flow and large volume spring discharges. The high vertical conductivity allows recharge to quickly drain through the shallow and undeveloped soils and intersect large deep aquifers, where residence times can be on the scale of years or decades (Jefferson et al., 2006). In the WC, greater drainage efficiencies due to steep lateral hydraulic gradients, shallow bedrock, and clay aquitards confine recharge to the shallow subsurface region,

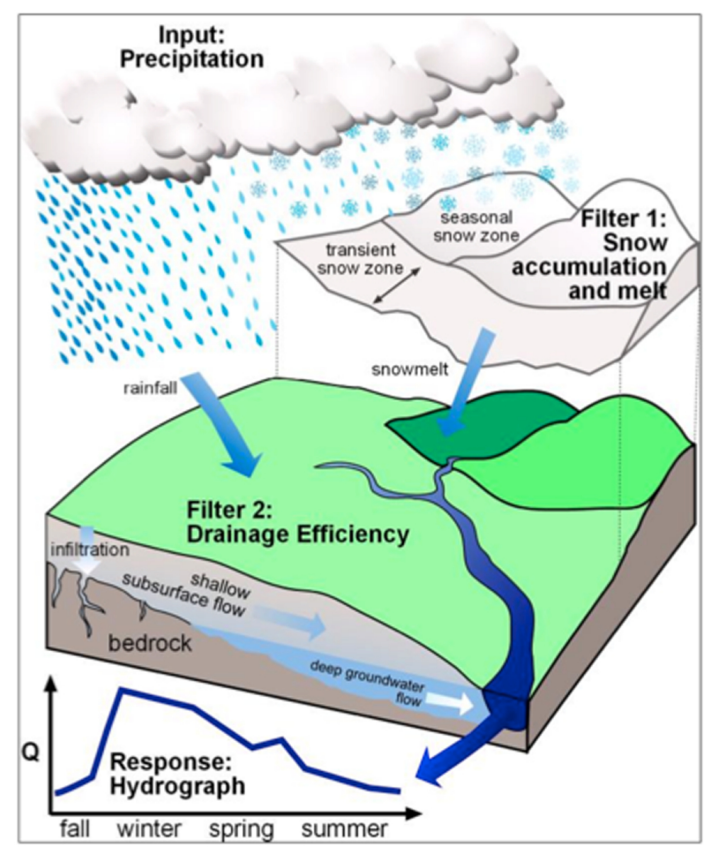

Fig. 1. Landscape responses to precipitation inputs - as a series of filters (Tague and Grant, 2009).

producing quicker transfer of recharge to streamflow (Tague and Grant, 2004). These differences in flowpaths, and therefore subsurface residence times, lead to distinctively different hydrologic regimes, characterized by higher baseflows, slower recessions, and muted flood peaks in $\mathrm{HC}$ watersheds (Tague and Grant, 2009). During winter storm and early spring snowmelt peaks, recharge in WC regions quickly enters streams, contributing a greater portion to flow than in $\mathrm{HC}$ regions. During summer periods, months after the last substantial precipitation has fallen, the groundwater storage in WC systems is largely depleted (Jefferson et al., 2006), and the pattern reverses as the majority of flow in the McKenzie originates from slow-draining HC aquifers (Tague and Grant, 2004).

Given these geologic distinctions, we hypothesize that geologic classification should be a good indicator of drainage parameters for hydrologic models. To assess whether geology can be used as an effective parameter transfer approach, we compare the estimated parameters using model calibration against observed streamflow across a range of scales for WC watersheds, and compare with parameters estimated for $\mathrm{HC}$ watersheds. We then investigate the implications of using a "generalized" WC and HC parameter set for predicting streamflow responses to warming and test model performance for a watershed that includes both HC and WC geology, where spatial patterns of drainage parameters within the watershed are assigned based on these generalized values, derived from calibration of end member WC and $\mathrm{HC}$ watersheds. We then explore how model assessments of climate 
warming impacts on streamflow seasonality respond to these strategies for assigning drainage parameters.

\section{Methods}

RHESSys (Tague and Band, 2004) is a physically based, spatially distributed, hierarchical daily time-step model that couples watershed hydrology, vegetation growth, and soil biogeochemical cycling processes. It models both vertical and lateral hydrologic processes. As a spatial model, RHESSys discretizes the landscape into a hierarchy of spatial objects including: watersheds; hillslopes, which drain to either side of a stream reach; zones, which are areas of similar meteorological forcing within hillslopes; and finally patches, which are typically 30 to $90 \mathrm{~m}$ scale modeling units. Most vertical processing of hydrologic and carbon cycling processes is done at the patch scale; while shallow subsurface moisture redistribution occurs between patches at the hillslope scale, and a deeper groundwater store is also modeled at the hillslope scale. The shallow subsurface flow model considers four layers: (1) a surface detention store, (2) rooting zone, (3) unsaturated store, and 4) saturated zone store, and routes this surface and shallow subsurface water laterally between model units (30-120 $\mathrm{m}$ patches) based on topography and soil drainage parameters. Transpiration of infiltrated water, as well as evaporation of water from interception, litter, and soil is estimated using the Penman-Monteith approach. Deeper groundwater flow of water that bypasses the shallow subsurface flow system is modeled at a coarser hillslope scale (unit draining either side of a stream reach) using a linear storage-discharge relationship. RHESSys has been applied in a number of mountain catchments in the Western US (Baron et al., 2000; Tague and Grant, 2009), as well as mountainous catchments in Europe (Zierl et al., 2006), and evaluated against respective catchment observed streamflow, snow, carbon and moisture flux data. The model's physical treatment of rain and snow partitioning, snow melt, shallow and deep groundwater flow, and evapotranspiration make it a suitable tool for studying the impacts of global change on mountain hydrology. Details of RHESSys process representation are summarized in Tague and Band (2004).

RHESSys model inputs consist of meteorological time series data and GIS-based inputs of topography, soils, land use, and land cover. For simplicity, we use data from a single meteorologic station as input. While this paper focuses on the role of subsurface drainage uncertainty, another key challenge in estimating streamflow in mountain environments is distributing meteorological and, in particular, precipitation data. For this study, we account for spatial variation in precipitation using a single meteorological station combined with widely available PRISM mean annual precipitation grids (Day et al., 1994) to derive spatially variable estimates for daily precipitation data. For temperature, we also use the same meteorological station and adjust temperature input data based on standard elevational lapse rates. While additional meteorological stations are located within the watershed, long-term records at multiple meteorological stations are often unavailable. In contrast, approaches for interpolating climate data such as PRISM are available for wide geographic areas. Here we test how well streamflow characteristics can be predicted for different watersheds using commonly available data sets. Other GIS data sets, such as soils, land cover, and elevation, are obtained from the Oregon Geospatial Data Clearinghouse.

There are six hydrologic parameters that can be calibrated in RHESSys. Two parameters control soil transmissivity: $K$ $\left(\mathrm{m} \mathrm{day}^{-1}\right)$, the saturated hydraulic conductivity at the surface; and $m$ (meters), the exponential decay of saturated conductivity with depth; such that:

$K(z)=\exp (-z \rho / m)$.

Here $z$ is depth (m) below the surface and $\rho$ is porosity. Two parameters control soil moisture holding capacity: po - pore size index; and pa (meters of water), soil water potential at air entry; and two parameters control deeper ground-water drainage: gw 1 , the percentage of subsurface water that enters a deep groundwater storage, bypassing shallow subsurface flowpaths and rooting zone storage; and gw $2\left(\%\right.$ day $\left.^{-1}\right)$, the rate of drainage from the deep groundwater storage. The last two parameters are only included in parameterization if this deeper ground-water store is needed, i.e., for watersheds with HC geology (Tague and Grant, 2004). Where deep groundwater is not present, a simpler representation of subsurface drainage is obtained by setting gw 1 to 0 , thus using only a shallow subsurface flow representation in the watershed.

The gw 1 and gw2 parameters are used to characterize the deeper ground water systems that are well below the biological active soil and rooting zone. The other four parameters (po, pa, $m, K$ ) reflect soil characteristics and shallow subsurface flowpaths. We hypothesize that the younger, deeper groundwater dominated $\mathrm{HC}$ region will lead to higher values of gw1. We also note, however, that soil water-holding capacity (parameters po and pa) and shallow subsurface drainage ( $m$ and $K$ ) are also likely to depend on the time taken for soil development. Western Cascade soils are derived from bedrock that has weathered in place for up to 30 million years, over which time a wide range of clay species have developed forming impervious layers and aquacludes. Infiltration rates are high with abundant residual stones and clasts (Dyrness, 1969), and soils are shallow due to mass wasting and creep. In contrast, $\mathrm{HC}$ soils are much younger (less than seven million years) and typically lack abundant clays and corresponding impermeable layers. They also occupy much lower gradient portions of the landscape, meaning that hydraulic gradients are gentler.

RHESSys was calibrated independently for seven gaged watersheds in the upper McKenzie watershed, including two $\mathrm{HC}$ watersheds and five WC watersheds (Table 1, Fig. 2). The two HC watersheds are McKenzie River at Clear Lake 
Table 1. Watershed characteristics.

\begin{tabular}{lllcl}
\hline $\begin{array}{l}\text { Watershed } \\
(\mathrm{WS})\end{array}$ & Abbreviation & $\begin{array}{l}\text { Drainage } \\
\left(\mathrm{km}^{2}\right)\end{array}$ & $\begin{array}{c}\text { Elevation } \\
(\mathrm{m})\end{array}$ & Geology \\
\hline $\begin{array}{llll}\text { Budworm Creek } \\
\text { Lookout Creek }\end{array}$ & BUD & $7.77(54.5)$ & $619-1626$ & WC \\
Mack Creek & MACK & 5.8 & $728-1620$ & WC \\
Watershed 2 & W2 & 0.60 & $548-1610$ & WC \\
Watershed 8 & W8 & 0.22 & $993-1170$ & WC \\
Clearlake & CLR & 239.3 & $924-2019$ & HC \\
Horse Creek & HORSE & 387.5 & $439-3152$ & HC \\
Southfork & SF & 538.7 & $530-2044$ & $36 \% \mathrm{WC} ;$ \\
& & & & $64 \% \mathrm{HC}$ \\
\hline
\end{tabular}

(CLR) and Horse Creek near McKenzie Bridge (HORSE). The five WC watersheds are Budworm Creek near Belknap Springs (BUD) and Lookout Creek (HJA), along with three sub-watersheds within the Lookout Creek drainage (MACK Creek, W2, and W8). The number of HC watersheds considered was limited by the small number of gaged watersheds draining predominately $\mathrm{HC}$ geology. All seven watersheds were calibrated for two water years, following a single year of spin-up. All watersheds were run across the same 1500 randomly generated parameter sets by sampling from a uniform random distribution within realistic ranges for each of the six parameters. For 300 of the 1500 parameter sets, we set gw1 equal to 0 in order to run a simpler (and more parsimonious) model. Realistic ranges for each parameter were established based on RHESSys parameter libraries. We used two performance metrics, the Nash-Sutcliffe Efficiency (NSE) and the NSE of log-transformed flow (NSElog), to evaluate the parameter sets. The Nash-Sutcliffe Efficiency is a commonly used metric for evaluating streamflow predictions from hydrologic models. Because streamflow in this region has a high dynamic range (high winter peaks and low summer flows), we add the NSE of log-transformed flows to test whether the model can capture recession and summer flow behavior as well as storm flows.

For each watershed, we compared the number of acceptable parameter sets as well as sensitivity of model performance to each parameter. We examine how acceptable parameter values differ between $\mathrm{HC}$ watersheds and $\mathrm{WC}$ watersheds relative to comparisons of acceptable parameter sets within WC watersheds alone. The parameter sets are considered acceptable if the NSElog value $>0.5$; we also consider a more stringent criterion $>0.8$. We then define our generalized $\mathrm{HC}$ parameter sets as those that are acceptable for both of the two $\mathrm{HC}$ watersheds and our generalized WC parameter sets as those that are acceptable for all five WC watersheds. To test model performance, we selected four calibrated parameter sets from the generally acceptable data set and ran RHESSys for all years for which streamflow is available ( $>25$ water years for most watersheds). Parameter sets were selected to cross a range of different parameter values,

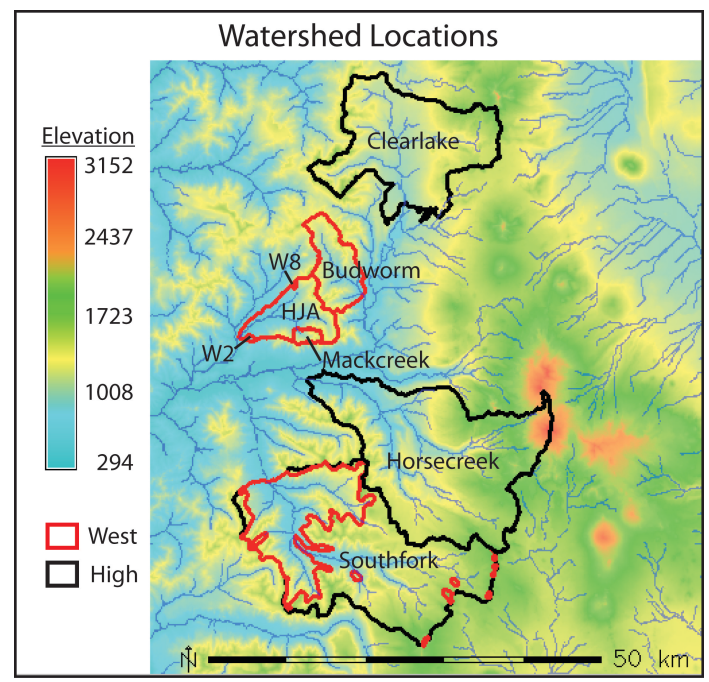

Fig. 2. Map showing study watersheds (listed in Table 1) and geologic classification.

but all gave model results within the acceptable performance criteria.

To assess the use of geologic classification as a method for assigning hydrologic parameters, we apply RHESSys to the South Fork McKenzie (SF) watershed (comprised of both HC and WC geology; Table 1, Fig. 2). We use an endmember mixing approach, where drainage parameters within SF are assigned based on drainage parameters for "pure" WC and $\mathrm{HC}$ watersheds. In other words, parameters are varied spatially according to $\mathrm{HC} / \mathrm{WC}$ geologic classification within the SF watershed. The pure "WC" and "HC" parameters are the generally acceptable drainage parameters from the calibrations of $\mathrm{HC}$ and WC described above. Thus, for the portion of SF with HC geology (approximately $64 \%$ of the drainage area), we use parameter sets that had acceptable performance from the CLR and HORSE calibrations. For the WC portion (36\%), we use parameter sets that had acceptable performance across all five WC watersheds.

NSE is a commonly used performance metric and values about 0.5 are often considered acceptable. Nonetheless, assessing how "good" is "good enough" depends on the application of the hydrologic model. For this study, we base our assessment of "good enough" on the ability of the model to capture changes in seasonality of streamflow with climate warming. In climate change assessment within the Western US, a frequently used measure of streamflow change with warming is the spring fraction of total annual streamflow. Studies have shown that as snowpacks decline, the late spring and early summer fraction of total annual flow also declines (Regonda et al., 2005; Stewart et al., 2005). To examine whether model performance for the SF watershed using the generalized parameter sets is "good enough", we examine the correlation between observed and modeled spring fraction of flow. We define spring as April-June. We then 

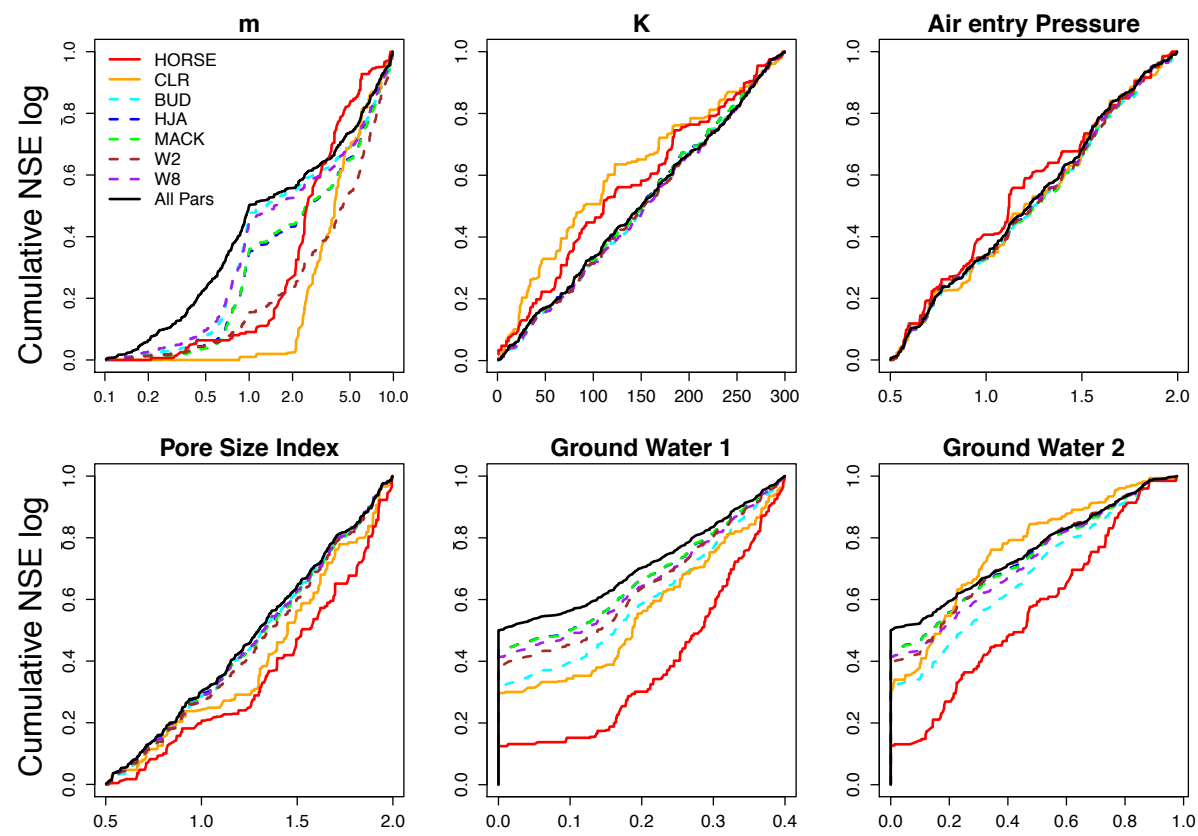

Fig. 3. Cumulative distribution of performance across parameter sets. The y-axis gives the cumulative probability of the performance measure (or parameter distribution). The x-axis gives the value of the parameter. Solid black line shows the original parameter distribution; colored lines show distribution of performance by parameter value for each watershed. Departures from the black line show preference for particular parameter values.

simulate the response of SF and other watersheds to both 2 and $4{ }^{\circ} \mathrm{C}$ warming scenarios (using one of the best performing parameter sets), and assess whether predicted changes are small or large relative to error in predicting historic streamflow response to inter-annual climate variability. We apply a uniform temperature increase to historic meteorologic forcing data to generate the warming scenarios. Predicted future warming scenarios in the PNW range between one and eight degrees (Mote and Salathe Jr., 2010). We acknowledge that a uniform warming scenario is simplistic and actual climate warming will be more temporally complex; we use it here, however, to assess the sensitivity of modeled streamflow to changes in temperature, given different assumptions about drainage parameters.

\section{Results}

Figure 3 illustrates the cumulative performance across parameter values for each of our six calibration parameters within each of the seven calibration watersheds. Following Thorndahl et al. (2008), we examine model sensitivity to specific parameters by comparing this cumulative performance distribution with the cumulative distribution of parameter values. Calibration preference (or improved performance) for particular parameter values is demonstrated by a shift of the cumulative distribution of NSE or NSElog for that parameter relative to its cumulative distribution within the calibration set (shown in Fig. 3 as a solid black line - this can be interpreted as the reference distribution). Generally, departures above the reference distribution indicate preference for parameter values in that range and vice-versa. Results were similar using the NSE performance metric so only NSElog results are shown. The greatest difference in acceptable parameter distributions occurs between $\mathrm{HC}$ and WC sites; this difference is present for all parameters. Relative to the WC watersheds, the HC watershed CLR shows improved performance for higher values of $\mathrm{gw} 1$, lower values of $\mathrm{gw} 2$, higher values of $m$, and lower values of $K$. This set of parameters for a $\mathrm{HC}$ watershed reflect a slower draining system with greater proportions of infiltrated water connecting to a deeper groundwater reservoir. The $\mathrm{HC}$ watersheds also show a slightly different responses to air entry pressure (pa) and pore size index (po). All sites show a strong sensitivity to $m$ (e.g., cumulative distribution of NSElog across $m$ parameter shows the greatest departure from the distributions of parameters within the calibration data set). For the $m$ parameter, there are also differences within the WC sites, particularly for W2. Higher values of $m$ show improved performance in W2 relative to other WC sites. The distinctive calibrated parameters for $\mathrm{W} 2$ relative to other WC watersheds may suggest actual difference in drainage characteristics. We note, however, that parameters associated with W2 may alternatively reflect potential errors in stream gage measurement, since previous hydrologic analysis in W2 using a water-balance approach suggests that approximately $20 \%$ of streamflow may be lost as deep groundwater and not captured by the gage (Waichler 
Table 2. Number of acceptable parameters sets for each watershed.

\begin{tabular}{lll}
\hline WS & $\begin{array}{l}\text { Initial Criteria } \\
(\text { NSElog }>0.5)\end{array}$ & $\begin{array}{l}\text { Stringent Criteria } \\
(\text { NSElog }>0.8)\end{array}$ \\
\hline CLR & $17(3 \%)$ & 0 \\
HORSE & $11(2 \%)$ & 0 \\
BUD & $266(44 \%)$ & $20(3 \%)$ \\
HJA & $431(72 \%)$ & $185(31 \%)$ \\
MACK & $404(67 \%)$ & $152(25 \%)$ \\
W2 & $327(55 \%)$ & $126(21 \%)$ \\
W8 & $376(63 \%)$ & $111(19 \%)$ \\
\hline
\end{tabular}

et al., 2005). Improved performance for WC watersheds occurred with lower values of $m$ relative to $\mathrm{HC}$ watersheds. Lower values of $m$ denote a steeper decline in hydraulic conductivity with depth, and are consistent with shallower hydrologically active soils. This result is consistent with the more well-developed clay and bedrock confining layers associated with the older WC geology.

Table 2 summarizes the number of acceptable parameter sets for each watershed. The watersheds differ in terms of the percentage of parameter sets that achieved an acceptable level of performance, where acceptable was defined as NSElog $>0.5$. HJA had the highest (72\%) number of parameters that achieved acceptable performance, while HORSE had the lowest ( $2 \%$ ). There were 173 parameter sets that were acceptable for all WC sites (10\% of parameters, based on NSElog $>0.5$ criteria). None of the parameter sets that achieved acceptable performance for the WC sites also achieved acceptable performance for the $\mathrm{HC}$ sites. In other words, the set of acceptable parameters for the WC sites were mutually exclusive from those for the $\mathrm{HC}$ sites. Within the WC sites, however, there was substantial, although not complete, overlap of acceptable parameter sets.

There was some variation in overall performance in the calibration period between different sites. In general, sites with a larger number of acceptable parameters had higher overall performance. To try to further constrain parameter values, we consider a more stringent criteria, defined as NSElog $>0.8$ (Table 2). Using these more stringent criteria, there remain 17 parameter sets that are acceptable across BUD, HJA, MACK, and W8 sites. However, W2 parameter sets do not overlap with the other sites if these more stringent criteria are used. This difference in W2 performance reflects its differing sensitivity to the $m$ parameter as discussed above.

There are parameter sets that have gw1 set to 0 within those that are acceptable for BUD, HJA, MACK, and W8 using these more stringent criteria. We consider these sets to be preferable, given that they result in a simpler (more parsimonious) model because the deeper groundwater store is not used. It is worth noting that none of the acceptable parameter
Table 3. Example of an acceptable parameter set across common geologic watersheds.

\begin{tabular}{lcccccc}
\hline WS & $\begin{array}{c}\mathrm{M} \\
(\mathrm{m})\end{array}$ & $\begin{array}{c}\mathrm{K} \\
\left(\mathrm{m} \mathrm{day}^{-1}\right)\end{array}$ & $\begin{array}{c}\text { pa } \\
(\mathrm{m})\end{array}$ & $\begin{array}{c}\text { po } \\
(\mathrm{dim})\end{array}$ & $\begin{array}{c}\text { gw2 } \\
(0-1)\end{array}$ & $\begin{array}{c}\text { gw2 } \\
(0-1)\end{array}$ \\
\hline CLR & 5.1 & 34 & 0.9 & 1.6 & 0.3 & 0.6 \\
HORSE & 5.1 & 34 & 0.9 & 1.6 & 0.3 & 0.6 \\
BUD & 0.8 & 58 & 1.8 & 1.1 & 0 & 0 \\
HJA & 0.8 & 58 & 1.8 & 1.1 & 0 & 0 \\
MACK & 0.8 & 58 & 1.8 & 1.1 & 0 & 0 \\
W8 & 0.8 & 58 & 1.8 & 1.1 & 0 & 0 \\
W2 & 1.8 & 249 & 1.8 & 1.3 & 0.2 & 0.6 \\
\hline
\end{tabular}

sets for the $\mathrm{HC}$ watershed have gw 1 set to 0 . Thus, for the $\mathrm{HC}$ watersheds, a deeper groundwater store must be included.

For validation, we randomly selected four parameter sets from those that were considered acceptable for the WC sites and then for the $\mathrm{HC}$ sites, respectively, using the more stringent selection criteria. We argue that any of these parameter sets could be selected as the "best" parameter set in a calibration process, depending on the criteria used or the calibration period. We examine results from four parameters within the acceptable set to ensure that our results are not overly dependent on which "acceptable" parameter set is chosen. For BUD, HJA, MACK, and W8, we use parameter sets that met the more stringent criteria for all sites, and two that did not include a deeper groundwater store (gw1 was set to 0 ). We consider these parameters to be examples of WC end-member parameter sets. We exclude W2 calibrations from developing the end-member WC parameter set because of their deviation from other WC watersheds and the evidence of observation error as the cause of this difference as noted above. For W2 simulations itself, however, we use parameters that met the more stringent criteria for $\mathrm{W} 2$ and the initial criteria for all WC sites. For HORSE and CLR, we randomly selected four parameter sets that met the more stringent criteria for both of those sites, and consider these parameters to be examples of $\mathrm{HC}$ end-member parameters. Table 3 summarizes one of the parameter sets selected.

Table 4 summarizes model performance for a seven-year evaluation period that is common across all watersheds (except HORSE, which had very few years of overlap) and for a longer period using the full streamflow record available for each watershed. As expected, all watersheds show some degradation in performance over the evaluation periods relative to the two-year period used for calibration. Nonetheless, all watersheds show at least reasonable performance for the common evaluation and longest evaluation periods, with NSElog above 0.6 and NSE above 0.4 in most cases. Watersheds do differ in terms of long-term performance, with HORSE and CLR showing lower NSElog values than other watersheds. We note that Horse and CLR are located farthest 
Table 4. Model performance across four chosen parameters.

\begin{tabular}{|c|c|c|c|c|c|c|c|}
\hline \multirow[t]{2}{*}{ WS } & \multicolumn{2}{|c|}{$\begin{array}{c}\text { Calibration } \\
\text { (WY 1999-2000) }\end{array}$} & \multicolumn{3}{|c|}{$\begin{array}{c}\text { Evaluation } \\
\text { (longest period) }\end{array}$} & \multicolumn{2}{|c|}{$\begin{array}{c}\text { Evaluation } \\
\text { (WY 1980-1986) }\end{array}$} \\
\hline & NSElog & NSE & NSElog & NSE & Eval. period & NSElog & NSE \\
\hline CLR & $.51-.67$ & $.30-.68$ & $.61-.68$ & $.55-.56$ & WY 70-06 & $.54-.62$ & $.50-.53$ \\
\hline HORSE & $.50-.62$ & $.46-.65$ & $.52-.59$ & $.40-.48$ & WY 62-69 & NA & NA \\
\hline BUD & $.80-.83$ & $.62-.68$ & $.68-.75$ & $.40-.45$ & WY 79-86 & $.67-.74$ & $.40-.44$ \\
\hline HJA & $.82-.91$ & $.72-.82$ & $.68-.82$ & $.47-.60$ & WY 58-05 & $.70-.80$ & $.49-.62$ \\
\hline MACK & $.85-.91$ & $.60-.70$ & $.68-.76$ & $.41-.49$ & WY 80-06 & $.56-.69$ & $.40-.53$ \\
\hline W2 & $.83-.91$ & $.51-.61$ & $.69-.75$ & $.36-.44$ & WY 58-06 & $.66-.74$ & $.31-.43$ \\
\hline W8 & $.88-.89$ & $.60-.66$ & $.74-.75$ & $.35-.37$ & WY 64-05 & $.69-.72$ & $.39-.46$ \\
\hline SF & NA & NA & $.75-.80$ & $.58-.66$ & WY 58-88 & $.68-.75$ & $.59-.69$ \\
\hline
\end{tabular}

from the meteorologic station, and thus are most susceptible to errors in spatial interpolation of precipitation.

To demonstrate the effectiveness of end-member parameters for the WC region, we compute the range of NSElog values obtained for full simulation period for each WC watershed using only the set of parameters that were acceptable for all other WC watersheds (Table 5). We exclude W2 from this analysis. Essentially, these show the range of performance that would have been obtained for that watershed if parameters were based on acceptable WC end-member parameter sets, rather than calibration of that particular watershed. Acceptable end-member parameters were based on calibration of the other WC watersheds. Results show good performance for all WC watersheds, including the nested watersheds within the HJA (W8 and MACK) as well as the neighboring watershed (BUD). We could not repeat this experiment for $\mathrm{HC}$ because we were limited to only two endmember $\mathrm{HC}$ watersheds. However, generalization of $\mathrm{HC}$ parameters is supported by results from the mixed-geology SF watershed, as discussed below.

Streamflow predictions for SF, resulting from a set of parameters transferred using the geologic end-member mixing described above, show good correspondence between observed and modeled flows (Fig. 4). Based on our initial model implementation using this approach, streamflow predictions were consistently $20 \%$ lower than observed streamflow across all parameter sets. The long-term bias of $20 \%$ in total streamflow likely reflects a bias in input rather than drainage parameters, which tend to influence the hydrograph shape. Error in precipitation input estimates is not surprising given that precipitation inputs are based on a meteorologic station more than $27 \mathrm{~km}$ from SF. Although PRISM was also used to scale precipitation from the meteorologic site, PRISM grids are also relatively coarse $(200 \mathrm{~m})$. Since the focus of this paper is on drainage parameters, we simply applied a $20 \%$ increase in precipitation input to the model to account for the difference. We note, however, that the necessity of post-hoc precipitation adjustment illustrates the sensitivity to precipitation interpolation (or downscaling for GCM
Table 5. Effectiveness of end-member parameters for the WC region.

\begin{tabular}{lccc}
\hline & $\begin{array}{c}\text { Min } \\
\text { NSElog }\end{array}$ & $\begin{array}{c}\text { Mean } \\
\text { NSElog }\end{array}$ & $\begin{array}{c}\text { Max } \\
\text { NSElog }\end{array}$ \\
\hline BUD & 0.67 & 0.77 & 0.85 \\
HJA & 0.57 & 0.85 & 0.93 \\
MACK & 0.65 & 0.86 & 0.91 \\
W8 & 0.84 & 0.87 & 0.91 \\
\hline
\end{tabular}

inputs), which is an ongoing area of research. Further work using improved precipitation input estimates will also test whether under-prediction reflects geologic controls. In particular, the disorganized drainage of the HC portion of SF may in some cases lead to inter-basin subsurface water transfers. This effect was shown to be small for the CLR watershed and we do not expect it to be a significant loss here but further work would be needed to confirm this. Performance metrics for 16 combinations of parameters (four different examples of $\mathrm{HC}$ end-member parameters paired with four examples of WC end-member parameters), after the precipitation adjustment, are summarized in Table 4.

Model results for SF show relatively minor degradation in performance relative to the other watersheds that used calibrated parameters. For the common evaluation period, NSE for calibrated watersheds ranges from 0.59 to 0.69 and NSElog from 0.68 to 0.75 . Performance measures for SF are within or even better than these ranges. For the longest evaluation period, SF produces performance metrics within the ranges produced by the watersheds for the calibration period. Figure 5 shows modeled streamflow for SF for one water year, using a parameter set based on our geologic end-member mixing approach. We compare this prediction to predictions using only $\mathrm{WC}$ or $\mathrm{HC}$ parameters. When SF is run as an all WC watershed, winter peaks are overpredicted and summer flows underpredicted. When SF is run as an all $\mathrm{HC}$ watershed the opposite bias occurs. Thus, when WC parameters are used for SF, we get a reasonable NSE 

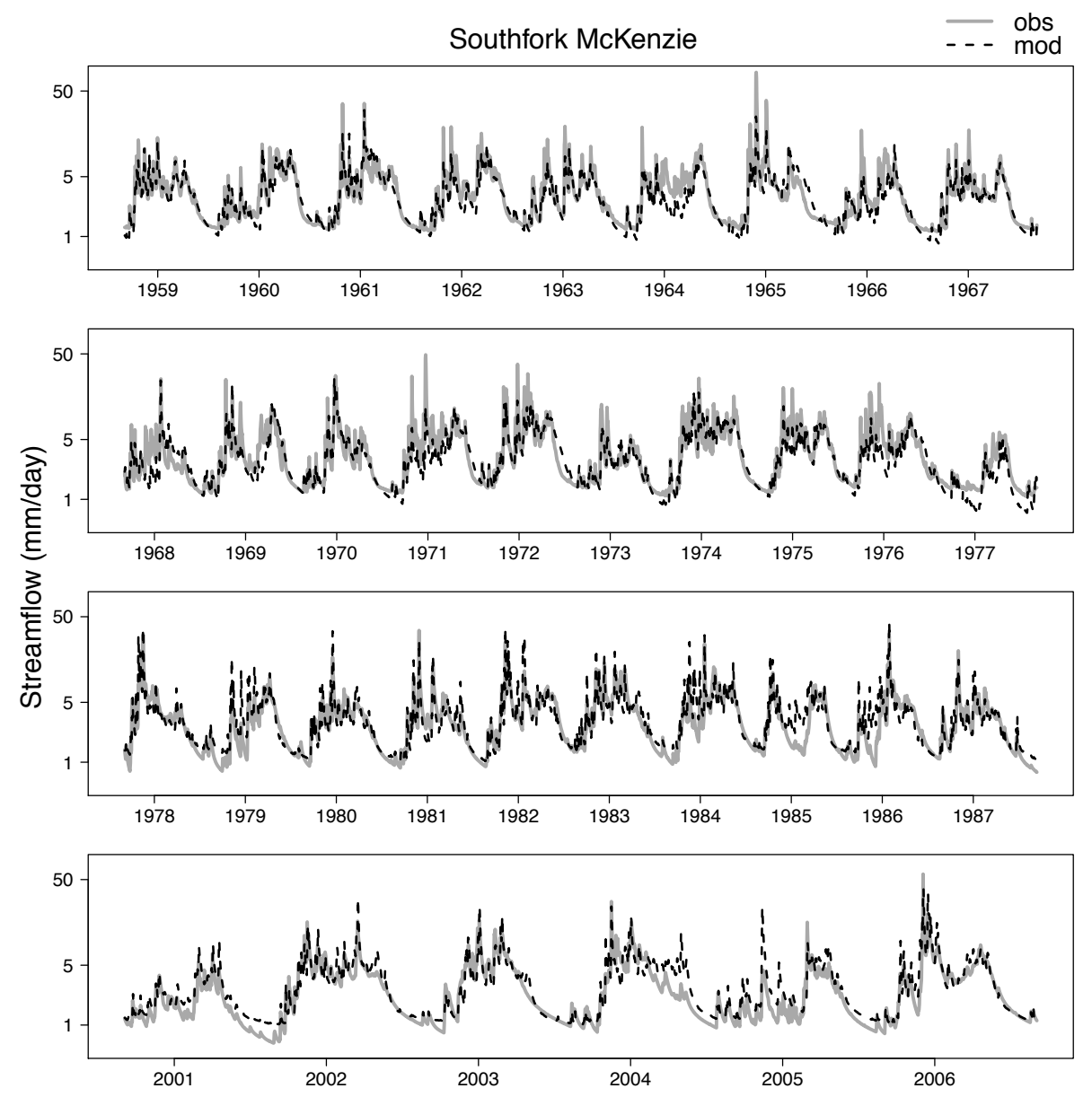

Fig. 4. Southfork watershed streamflow, modeled and observed. Modeled streamflows are generated using geologic end-members to assign soil drainage parameters.

(0.71), but a much low NSElog (0.28). When HC parameters are used for SF, we get a reasonable NSElog (0.83), but a lower NSE (0.65). Using a combination of HC/WC in the end-member mixing approach substantially improves performance and obtains high NSE and NSElog performance measures $(0.83,0.9$ respectively). Differences in performance using spatially uniform $\mathrm{HC}$ or WC parameters versus spatially explicit parameter sets suggest that hydrologic behavior of SF reflects its mixed geologies, which include flow from both the relatively fast shallow subsurface dominated WC geology and the slower deeper groundwater dominated HC geology.

If end-member drainage parameters are used, all sites show statistically significant ( $p$-value $<0.001$ ) relationships between observed and modeled estimates of inter-annual variation in spring fraction of annual flow (Fig. 6). Correlation coefficients of the relationship between observed and modeled inter-annual variation in spring flow fraction range from 0.6 to 0.9. Lowest correlations occur for CLR. Good correlation between observed and modeled estimates of interannual variation in spring fraction of annual flow suggest that the model captures historically driven climate variation in the seasonality of flow for all sites.

For most sites, model estimates of long-term means of spring fraction were not significantly different from observed values (Fig. 7a). The exception is W2, where modeled means of spring fraction were significantly higher than observed values. As noted above, W2 model results tend to overestimate flow in general and may reflect stream gage limitations. Overestimation of spring fraction by the model would therefore be expected given that more flow occurs during the spring. Interestingly, W2 shows the highest correlation between historic inter-annual variations in observed versus modeled spring fraction (Fig. 6) - again suggesting that the model captures response to climate variation but that there is an overall bias in estimates of the volume of flow.

Finally, we test whether model estimates of spring fraction of flow for warming scenarios are significantly different from baseline estimates. For the $2{ }^{\circ} \mathrm{C}$ warming scenario (T2), CLR, HJA, MACK, and SF show statistically lower spring fractions. For the $4{ }^{\circ} \mathrm{C}$ warming scenario (T4), all watersheds except the more rain-dominated W2 show significant 

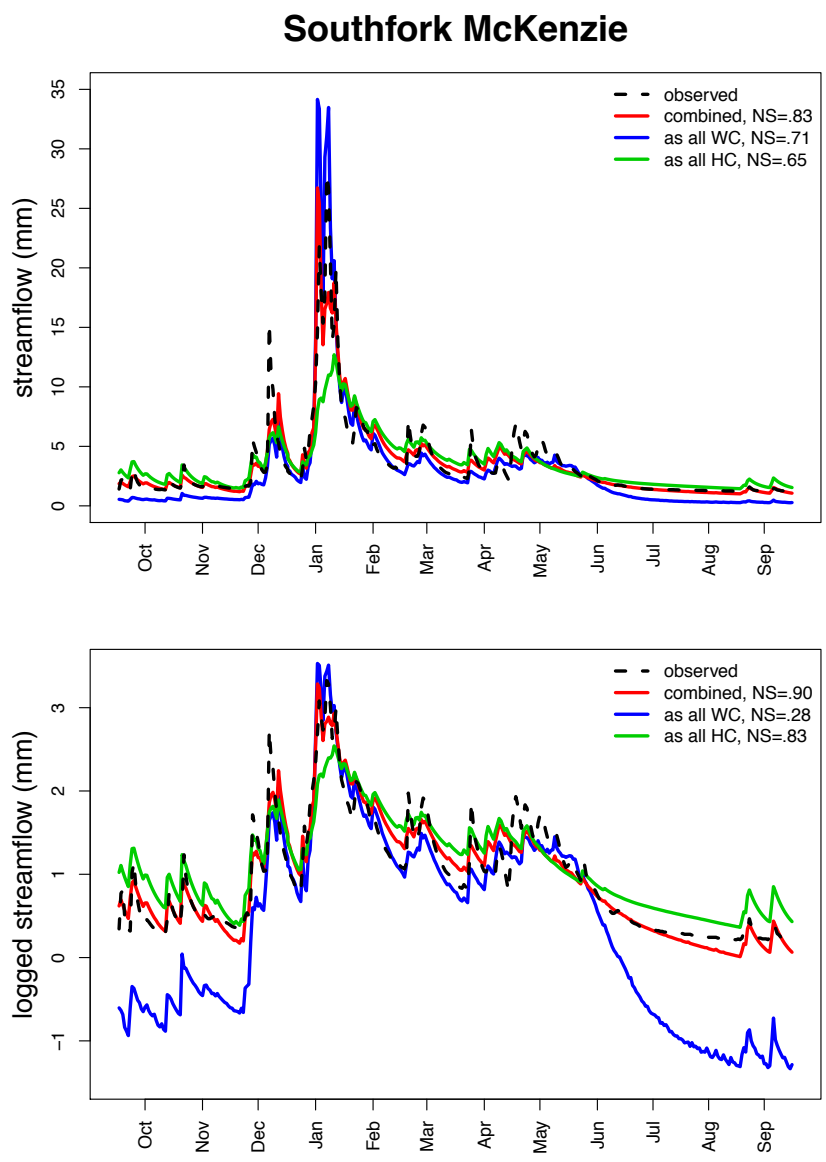

Fig. 5. Observed and modeled daily (a) streamflow and (b) logtransformed streamflow for South Fork McKenzie. Modeled streamflow estimates are shown for three parameter-transfer strategies including using only WC end-member parameters, only $\mathrm{HC}$ end-member parameters and combined strategy where parameters are varied spatially according to HC/WC geologic classification within the Southfork watershed.

reductions (Fig. 7a). For the SF watershed, changes in streamflow with warming are large relative to model error. Further, we show that for the SF watershed, changes in spring fraction of flow are substantially different across different assumptions regarding drainage parameters (Fig. 7b). Simulations using the $\mathrm{HC}$ watersheds show the least reduction in spring fraction of flow with warming, and also show almost no difference between T2 and T4 warming scenarios. If WC end-member parameters are used, the reduction in spring fraction of flow is greater, more variable from year to year, and shows a greater decline with more warming. Using the combined end-member approach, changes in seasonality with warming are intermediate between those found using the WC end-member and $\mathrm{HC}$ end-members alone. In this case, there is a moderate, though still substantial, reduction in spring fraction of flow with $2{ }^{\circ} \mathrm{C}$ warming, but with high inter-annual variation.
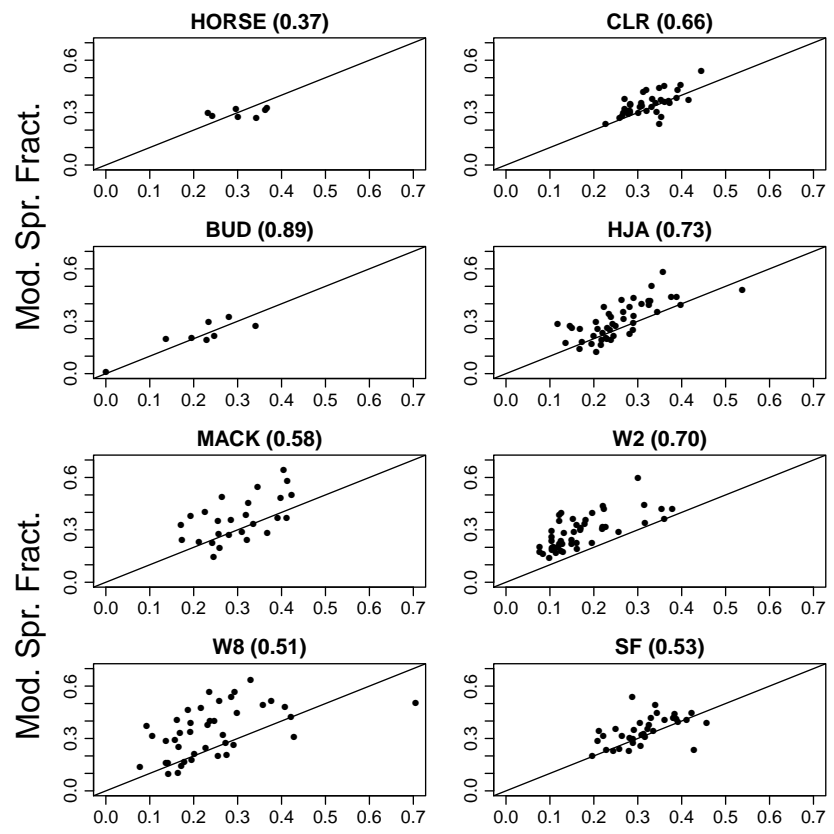

Obs. Spr. Fract.

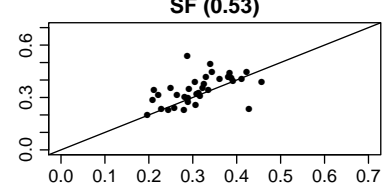

Obs. Spr. Fract.

Fig. 6. Correlation between observed and modeled spring fraction of annual flow. Values in brackets are Pearson Correlation Coefficient - all were significant at $99 \%$ confidence. Results are shown for a single acceptable parameter set and for all years with observed/modeled streamflow (available water years for each watershed are listed in evaluation column of Table 4).

\section{Discussion}

Comparison of drainage parameter sensitivity across multiple watersheds provides insight into underlying hydrologic behavior of these watersheds, and establishes a basis for deciding whether or not hydrologic parameters might be readily transferred from one watershed to another. For sites within the WC geologic region, we show that parameters can be readily transferred across scales ranging from a 4th order (HJA) to a 3rd order (MACK) to a 1st order (W8) watershed. Parameter sensitivity for HC sites was clearly different from WC sites, and is consistent with the interpretation presented in other modeling and empirical analyses (Tague et al., 2008; Jefferson et al., 2008) that suggest HC geology supports a slower draining, deeper groundwater system. Further, we show that for a watershed of mixed geology (SF), parameters from $\mathrm{WC}$ and $\mathrm{HC}$ end-member sets can be used to obtain reasonable streamflow estimates without calibration.

The success of parameter transferability based on this mappable HC/WC classification depends on (1) whether the $\mathrm{HC} / \mathrm{WC}$ geologic classification resolves dominant spatial differences in subsurface drainage behavior; (2) whether the model representation of spatial differences in snow accumulation and melt is adequate and not implicitly corrected for by drainage parameters; and (3) whether spatial variation in 

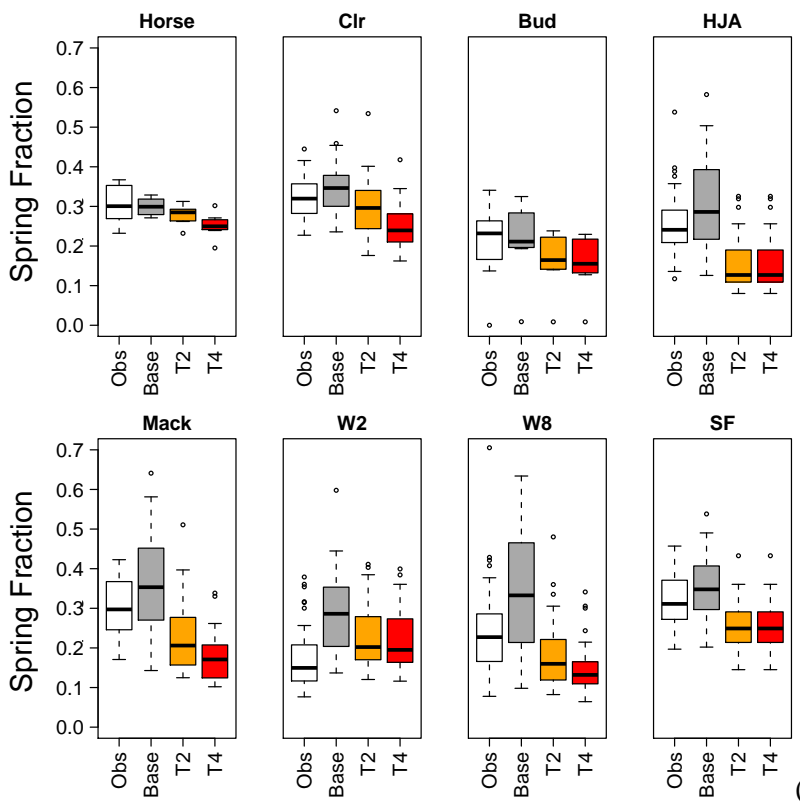

(a)

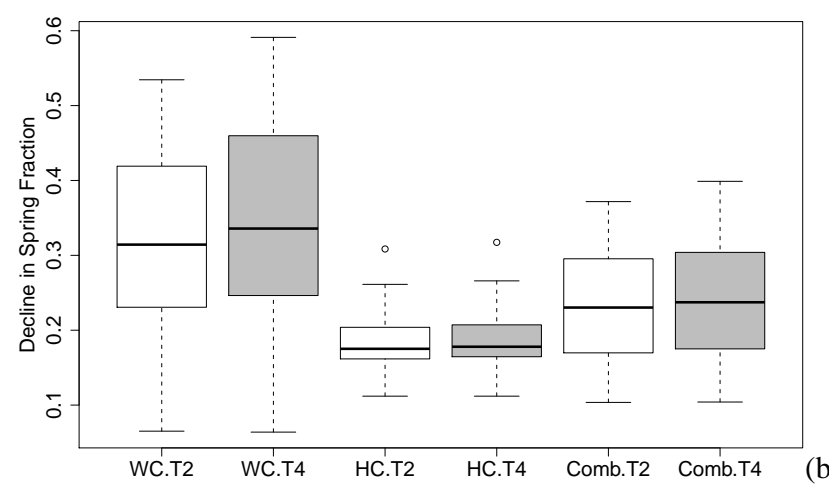

Fig. 7. (a) Variation in spring fraction of annual flow for modeled (white) and observed (gray) with historic climate (WY) and modeled results for a $2{ }^{\circ} \mathrm{C}$ (orange) and $4{ }^{\circ} \mathrm{C}$ (red) warming scenario. Results are shown for a single acceptable parameter set and for all years with observed/modeled streamflow (available water years for each watershed are listed in evaluation column of Table 4). (b) Change in modeled spring fraction of annual flow for $2{ }^{\circ} \mathrm{C}$ (white) and $4{ }^{\circ} \mathrm{C}$ (gray) warming scenarios in $\mathrm{SF}$ run as all WC, as all HC, and SF comprised of both $\mathrm{HC}$ and WC.

other inputs, including meteorologic forcing, is adequately represented. For the SF, the necessity of adjusting incoming precipitation magnitudes suggest that condition (3) is not met and more sophisticated schemes for interpolating precipitation data are needed. The relatively strong performance of SF once precipitation magnitudes (but not timing) were adjusted suggests that conditions (1) and (2) can be met within the larger McKenzie River watershed. For SF and other watersheds, model performance measured as NSE or NSElog was within the range commonly reported in other model-based studies within the Western US (e.g., Hay and Clark, 2003; Franz et al., 2008; Graves, 2007). We note that
RHESSys is a spatially distributed hydrologic model of intermediate complexity. Simpler hydrologic models (such as IHACRES; Littlewood and Jakeman, 1994) that use a lumped representation of fast and slow drainage systems may also be able to capture geologically based hydrologic differences between $\mathrm{HC}$ and WC systems. In these steep mountain watersheds, however, discretization of the landscape to account for spatial patterns of snow accumulation and melt would be more difficult to capture with these lumped models. In addition, accounting for within-watershed spatial redistribution of moisture may also impact evapotranspiration estimates by supporting higher ET in near stream areas or topographic hollows. RHESSys also accounts for coupled feedbacks between ecosystem carbon cycling, growth, and hydrology. This paper highlights that a relatively simple hydrologic parameterization scheme can be effective for this type of intermediately complex hydrologic model.

Ultimately, the evaluation of model performance depends upon the use of that model. Here we evaluate model performance relative to an assessment of the impact of simple climate warming on seasonality of streamflow. Specifically, we examined model estimates of the spring fraction of annual flow. For most study sites, our model estimates of mean spring fraction of flow and its inter-annual variation were not significantly different from observed flow given historic climate forcing. There are, however, notable differences in inter-annual mean and variation between observed and modeled estimates. One potential source of these errors would be errors in estimation of meteorologic inputs. Interpolation of both temperature and precipitation in mountain environments is a well-documented source of error in hydrologic models (Liston and Elder, 2006). Here we use a relatively simple approach where point meteorologic measurements of temperature are scaled using a constant environmental lapse rate of temperature with elevation, and precipitation is scaled based on long-term mean patterns derived from PRISM (Daly et al., 1994). Recent studies have shown that air temperature lapse rates with elevation are considerably more complex in this region, reflecting temperature inversions and cold air pooling (Lundquist and Cayan, 2007; Daly et al., 2007). Similarly, there are likely to be substantial errors in interpolating precipitation data for specific storm events. Our use of daily streamflow over several decades for model calibration and evaluation emphasizes long-term seasonal patterns of high and low flows and recession behavior - which are more likely to be sensitive to average climate and geology and are the focus of this paper. We therefore emphasize drainage parameter calibration and transferability, given expected uncertainties in meteorologic forcing. What is particularly encouraging is that even with these limitations, the SF watershed shows no degradation in performance relative to calibrated watersheds (based on predictions of spring fraction of flow). Future work will focus on disentangling the relative roles played by errors in meteorologic forcing and drainage properties. 
Results of warming scenarios show that geology and snow vs. rain are both important factors in the sensitivity of watersheds to warming. For all snow-dominated sites, a warming of $4{ }^{\circ} \mathrm{C}$ led to a statistically significant reduction in spring fraction. For the rain-dominated site it did not. These results are consistent with empirical findings (Mayer and Naman, 2011) on the sensitivity of streamflow to temperature in this region. For the $2{ }^{\circ} \mathrm{C}$ warming scenario, higher and more snow-dominated watersheds such as W8, did not show a significant reduction in spring fraction. In contrast, larger watersheds such as HJA and MACK that comprise a larger elevation range and include elevations typically at the boundary between rain-dominated and snow-dominated, did show a reduction in spring fraction for the $2{ }^{\circ} \mathrm{C}$ warming scenario. These modeled spatial differences in the sensitivity of streamflow to warming are consistent with both empirical and model-based literature records that demonstrate a linkage between reductions in spring fraction of flow, elevation, and warming for snow-dominated regions in the Western US (Stewart et al., 2005; Nolin and Daly, 2006). In addition to variation in the sensitivity of spring fraction to warming across snow-to-rain transitions, geologic differences are also important. Using only the end-member drainage parameters from the WC for the SF watershed resulted in greater and more variable estimates of the reductions in spring fraction of flow with warming relative to estimates using only $\mathrm{HC}$ drainage parameters, suggesting that greater drainage rates associated with WC geology enhance the sensitivity of the spring fraction of flow to warming. These results are consistent with our earlier model-based analysis which demonstrated that greater subsurface drainage rates in snow dominated catchments in the Western US tended to increase spring sensitivity to warming and decrease summer streamflow sensitivity (Tague and Grant, 2009; Safeeq et al., 2012). We note that differences in SF response across drainage parameters are solely due to the effect of subsurface effective conductivity/drainage rates since all other factors, including topography and changes in snow accumulation and melt, are held constant across the warming scenarios (Fig. 7b). These differences in response of SF watershed as a function of drainage parameters highlight the importance of accounting for geologically based differences in drainage rates in addition to topographic differences. Further, the emergence of end-member parameters that are consistent with mappable geologic classifications points to an approach for accomplishing this in the face of limited stream gage data.

These findings have broad implications for the use of distributed hydrologic models as a means of predicting downscaled streamflow response to climate warming, as is becoming increasingly common (Hamlet and Lettenmaier, 1999: Payne et al., 2004; Christensen et al., 2004; VanRheenen et al., 2004; Wood et al., 2004). Our results show that if predictions are needed in watersheds where calibrations have not been explicitly conducted, geology offers a potential method for assigning drainage parameters across a range of scales.
Further, our results suggest that in watersheds with mixed lithologies, which are the norm for larger watersheds, delineating sub-watershed areas of distinctive geology will be an important component of this parameter transfer approach. Lumping geologically distinctive areas within a watershed, on the other hand, is likely to lead to errors in transferring parameters.

\section{Conclusions}

The hydro-climatic setting in the McKenzie River watershed offers an illustrative example that may reflect other similar mountain systems, where spatial patterns of snow accumulation and melt are superimposed on geologically mediated differences in subsurface drainage and storage. In these settings, modeling the spatial response of streamflow to predicted climate change requires disentangling the spatial interaction between the static differences in subsurface drainage properties and the dynamic transition between rain and snow. To estimate how these systems will respond to climate variability and change, process-based modeling must represent the natural physical processes controlling runoff and capture relevant spatial differences in climate inputs and soil/drainage parameters. For climate inputs, limited spatial coverage by meteorologic stations with long-term records leads to the use of interpolation schemes such as PRISM, to account for spatial difference in climate inputs. Continued improvements in estimates of precipitation and temperature spatial-temporal patterns, both for retrospective and future analysis, are a critical research area. Limited spatial coverage of gaged streams to calibrate drainage parameters, however, is also an important factor and necessitates a strategy for drainage parameter transfer. In this paper, we demonstrate a successful drainage parameter transfer approach based on end-member parameter sets associated with mapped geologic classes. Streamflow estimation using this geologic end-member approach to transfer parameters was sufficient to capture historic climate variability for a set of watersheds that cross a range of scales from 1 st to 4 th order streams, including one watershed that comprised a mixture of geologic classes from both endmembers. Model error using this geologic end-member approach to assign drainage parameters was also small relative to changes in seasonal streamflow patterns associated with simple warming scenarios. For watersheds with a mixture of geology, assigning uniform parameters results in substantial degradation in flow, but perhaps more importantly, leads to substantially different estimates of the impact of warming on flow seasonality. These results argue the importance of accounting for drainage parameter heterogeneity and offer a method for doing so.

Our geologic end-member approach could be used to model hydrologic responses to climate warming for a range of watersheds within the McKenzie and potentially adapted for other areas of the mountainous Western US. The need for 
this type of multi-watershed modeling and parameterization approach is particularly important in assessments of climate change impacts on aquatic habitat, where the spatial patterns and diversity of hydrologic response within river watersheds may be important drivers of habitat quality and sensitivity to environmental change.

While the McKenzie watershed incorporates subwatersheds with sharply contrasting hydrogeologic terrains, it is by no means unique. Similar differences in drainage efficiencies would be expected in watersheds drained by both karstic and non-karstic lithologies, deeply weathered versus unweathered intrusive or sedimentary bodies, or glaciated versus non-glaciated terrain. Parameterization schemes for hydrologic models along the lines that we have outlined here offer a useful means of characterizing and interpreting the hydrologic differences among these varied settings. These schemes lend themselves well to modeling within and across "hydrologic landscapes", where landscapes are classified on the basis of their hydrologic behavior and similarities (i.e., Winter, 2001).

In sum, our analysis has shown that by defining a set of end-member parameters that reflect different geologic classes, we can more efficiently apply a hydrologic model over a geologically complex landscape. Unlike other parameters in a hydrologic model, such as vegetation leaf area index, drainage rates cannot be measured directly and are typically inferred from streamflow. Thus distributing these parameters in space is often limited by available data. A key advantage of our end-member approach is that it can account for within (and in between) watershed heterogeneity in drainage rates without the need for sub-watershed scale calibration.

We caution that our approach was based on the development of end-member parameter sets. Ideally, these parameter sets would be based on multiple calibrated watersheds within each geologic type. The multi-watershed calibration process here was used to evaluate whether geologic distinctions translate into a set of shared hydrologic parameters and thus provide acceptable end-member parameter sets. In the McKenzie watershed, a reasonably high density of gages, as well as a number of streams with pure HC and WC geologies, supported the development of these end-member parameters. In other more geologically heterogeneous regions, availability of pure end-members may be more limited. Remote sensing literature, which has a long history of deriving end-member sets, can provide numerous techniques for deriving end-member parameter sets from mixed observations. Further work will explore the use of this approach in these more geologically complex regions.

Acknowledgements. We gratefully acknowledge the reviewers of this paper for their many helpful remarks and corrections. In particular we thank Charles Luce for his very thoughtful review and comments. This research was conducted as part of the Western Mountain Initiative funded by US Geological Survey (USGS).
Edited by: M. Sivapalan

\section{References}

Barnett, T. P., Adam, J. C., and Lettenmaier, D. P.: Potential impacts of a warming climate on water availability in snow-dominated regions, Nature, 38, 303-309, 2005.

Baron, J. S., Hartman, M. D., Band, L. E., and Lammers, R. B.: Sensitivity of a high elevation Rocky Mountain watershed to altered climate and $\mathrm{CO}_{2}$, Water Resour. Res., 36, 89-99, 2000.

Beven, K. J.: Rainfall-Runoff Modelling: The Primer, John Wiley and Sons, Ltd., New York, 2001.

Christensen, N. S., Wood, A. W., Voisin, N., Lettenmaier, D. P., and Palmer, R. N.: Effects of climate change on the hydrology and water resources of the Colorado River Basin, Climatic Change, 62, 337-363, 2004.

Daly, C., Neilsen, R. P., and Phillips, D. L.: A StatisticalTopographic Model for Mapping Climatological Precipitation over Mountainous Terrain, J. Appl. Meteorol., 33, 140-158, 1994.

Daly, C., Smith, W., and Smith, J. I.: High-resolution spatial modeling of daily weather elements for a catchment in the Oregon Cascade mountains, United States, J. Appl. Meteorol. Climatol., 46, 1565-1586, doi:10.1175/JAM2548.1, 2007.

Dyrness, C. T.: Hydrologic properties of soils on three small watersheds in the western Cascades of Oregon, Res. Note PNW-111, US Department of Agriculture, Forest Service, Pacific Northwest Forest and Range Experiment Station, Portland, OR., 17 pp., 1969.

Farley, K. A., Tague, C., and Grant, G.: Vulnerability of water supply from the Oregon Cascades to changing climate: Linking science to users and policy, Global Environ. Change, 21, 110-122, 2011.

Franz, J., Hogue, T. S., and Sorooshian, S.: Operational snow modeling: Addressing the challenges of an energy balance model for National Weather Service forecasts, J. Hydrol., 360, 31-47, 2008.

Graves, C. H.: Hydrologic impacts of climate change in the Upper Clackamas River Basin, Oregon, USA, Clim. Res., 33, 143-158, 2007.

Hamlet, A. F. and Lettenmaier, D. P.: Effects of climate change on hydrology and water resources in the Columbia River Basin, J. Am. Water Resour. Assoc., 35, 1597-1623, 1999.

Hay, E. and Clark, M. P.: Use of statistically and dynamically downscaled atmospheric model output for hydrologic simulations in three mountainous basins in the western United States, J. Hydrol., 282, 56-75, 2003.

Hayhoe, K., Cayan, D., Field, C., Frumhoff, P., Maurer, E., Miller, N., Moser, S., Schneider, S., Cahill, K., Cleland, E., Dale, L., Drapek, R., Hanemann, R. M., Kalkstein, L., Lenihan, J., Lunch, C., Neilson, R., Sheridan, S., and Verville, J.: Emissions pathways, climate change, and impacts on California, P. Natl. Acad. Sci., 101, 12422-12427, 2004.

Hidalgo, H. G., Das, T., Dettinger, M. D., Cayan, D. R., Pierce, D. W., Barnett, T. P., Bala, G., Mirin, A., Wood, A. W., Bonfils, C., Santer, B. D., and Nozawa, T.: Detection and Attribution of Streamflow Timing Changes to Climate Change in the Western United States, J. Climate, 22, 3838-3855, 2009. 
Jefferson, A., Grant, G., and Rose, T.: Influence of volcanic history on groundwater patterns on the west slope of the Oregon High Cascades, Water Resour. Res., 42, W12411, doi:10.1029/2005WR004812, 2006.

Jefferson, A., Nolin, A., Lewis, S., and Tague, C.: Hydrogeologic controls on streamflow sensitivity to climate variation, Hydrol. Process., 22, 4371-7385, 2008.

Jefferson, A., Grant, G., Lewis, S., and Lancaster, S.: Coevolution of hydrology and topography on a basalt landscape in the Oregon Cascade Range, USA, Earth Surf. Proc. Land., 35, 803-816, doi:10.1002/esp.1976, 2010.

Jung, I. W. and Change, H.: Assessment of future runoff trends under multiple climate change scenarios in the Willamette River Basin, Oregon, USA, Hydrol. Process., 25, 257-278, 2010.

Knowles, N. and Cayan, D. R.: Potential effects of global warming on the Sacramento/San Joaquin watershed and the San Francisco estuary, Geophys. Res. Lett., 29, 1891-1894, 2002.

Liston, G. E. and Elder, K.: A meteorological distribution system for high-resolution terrestrial modeling (MicroMet), J. Hydrometeorol., 7, 217-234, doi:10.1175/JHM486.1, 2006.

Littlewood, I. G. and Jakeman, A. J.: A new method of rainfallrunoff modeling and its applications in catchment hydrology, in: Environmental Modelling, vol. 2, edited by: Zanetti, P., Computational Mechanics Publications, Southhampton, UK, 143-171, 1994.

Lundquist, J. D. and Cayan, D. R.: Surface temperature patterns in complex terrain: daily variations and long-term change in the central Sierra Nevada, California, J. Geophys. Res., 112, D11124, doi:200710.1029/2006JD007561, 2007.

Mayer, T. D. and Naman, S. W.: Streamflow response to climate as influenced by geology and elevation, J. Am. Water Resour. Assoc., 47, 724-738, doi:10.1111/j.1752-1688.2011.00537.x, 2011

Mote, P. W. and Salathé Jr., E. P.: Future climate in the Pacific Northwest, Climatic Change, 102, 29-50, doi:10.1007/s10584010-9848-z, 2010.

Nolin, A. and Daly, W. C.: Mapping at-risk snow in the Pacific Northwest, J. Hydrometeorol., 7, 1164-1171, 2006.

Null, S. E, Viers, J. H., and Mount, J. F.: Hydrologic Response and Watershed Sensitivity to Climate Warming in California's Sierra Nevada, PLoS ONE, 5, e9932, doi:10.1371/journal.pone.0009932, 2010.

Payne, J. T., Wood, A. W., Hamlet, A. F., Palmer, R. N., and Lettenmaier, D. P.: Mitigating the effects of climate change on the water resources of the Columbia River Basin, Climatic Change, 62, 233-256, 2004.

Regonda, S. K., Rajagopalan, B., Clark, M., and Pitlick, J.: Seasonal cycle shifts in hydroclimatology over the western United States, J. Climate, 18, 372-384, 2005.

Safeeq, M., Grant, G., Lewis, S., and Tague, C.: Coupling snowpack and groundwater dynamics to interpret historical streamflow trends in the Western United States, Hydrol. Process., doi:10.1002/hyp.9628, in press, 2012.

Sherrod, D. R. and Smith, J. G.: Geologic map of upper Eocene to Holocene volcanic and related rocks of the Cascade Range, Oregon, Geol. Invest. Ser. I-2569, US Geological Survey, Reston, Va., 17 pp., 2000.

Singh, V. P. and Woolhiser, D. A.: Mathematical modeling of watershed hydrology, J. Hydrol. Eng., 7, 270-292, 2002.
Stewart, I. T., Cayan, D. R., and Dettinger, M. D.: Changes toward earlier streamflow timing across western North America, J. Climate, 18, 1136-1155, 2005.

Tague, C. and Band, L.: RHESSys: Regional Hydro-ecologic simulation system: An object-oriented approach to spatially distributed modeling of carbon, water and nutrient cycling, Earth Interact., 8, 1-42, 2004.

Tague, C. and Grant, G.: A geological framework for interpreting the low flow regimes of Cascade streams, Willamette River Basin, Oregon, Water Resour. Res., 40, W04303, doi:10.1029/2003WR002629, 2004.

Tague, C. and Grant, G.: Groundwater dynamics mediate low flow response to global warming in snow-dominated alpine regions, Water Resour. Res., W07421, doi:10.1029/2008WR007179, 2009.

Tague, C., Farrell, M., Grant, G., Choate, J., and Jefferson, A.: Deep groundwater mediates streamflow response to climate warming in the Oregon Cascades, Climatic Change, 86, 189-210, 2008.

Thorndahl, S., Beven, K. J., Jensen, J. B., and Schaarup-Jensen, K.: Event based uncertainty assessment in urban drainage modelling, applying the GLUE methodology, J. Hydrol., 357, 421437, 2008.

Troch, P. A., Carrillo, G. A., Heidbüchel, I., Rajagopal, S., Switanek, M., Volkmann, T. H. M., and Yaeger, M.: Dealing with Landscape Heterogeneity in Watershed Hydrology: A Review of Recent Progress toward New Hydrological Theory, Geogr. Compass, 3, 375-392, doi:10.1111/j.1749-8198.2008.00186.x, 2009.

US EPA - US Environmental Protection Agency: EPA Region 10 Guidance for EPA Project \# 910-B-03-002, Pacific Northwest State and Tribal Temperature Water Quality Standards, Region 10 US EPA, Seattle, WA., 57 pp., 2003.

USGS - US Government: Streamflow Information for the Next Century: A Plan for the National Streamflow Information Program of the US Geological Survey, General Books LLC, Reston, Va., 20 pp., 1999.

Van der Linden, S. and Woo, M. K.: Transferability of Hydrological Model Parameters Between Basins in Data-Sparse Areas, Subarctic Canada, J. Hydrol., 270, 182-194, 2003.

VanRheenen, N. T., Wood, A. W., Palmer, R. N., and Lettenmaier, D. P.: Potential Implications of PCM Climate Change Scenarios for California Hydrology and Water Resources, Climatic Change, 62, 257-281, 2004.

Wagener, T. and Wheater, H. S.: Parameter estimation and regionalization for continuous rainfall-runoff models including uncertainty, J. Hydrol., 320, 132-154, 2006.

Waichler, S. R, Wemple, B. C., and Wigmosta, M. S.: Simulation of water balance and forest treatment effects at the H. J. Andrews Experimental Forest, Hydrol. Process., 19, 3177-3199, 2005.

Winter, T. C.: The concept of hydrologic landscapes, J. Am. Water Resour. Assoc., 37, 335-349, doi:10.1111/j.17521688.2001.tb00973.x, 2001

Wood, A. W., Leung, L. R., Sridhar, V., and Lettenmaier, D. P.: Hydrologic implications of dynamical and statistical approaches to downscaling climate model outputs, Climatic Change, 62, 189216, doi:10.1023/B:CLIM.0000013685.99609.9e, 2004.

Zierl, B., Bugmann, H., and Tague, C.: Evaluation of water and carbon fluxes in the ecohydrological model RHESSys, Hydrol. Process., 21, 3328-3339, 2006. 